\title{
A case of Clostridium septicum spontaneous gas gangrene
}

\author{
Joe Dylewski, MD; ${ }^{*}$ Robert Drummond, MD $;^{\dagger}$ John Rowen, $\mathrm{MD}^{\dagger}$
}

\begin{abstract}
Severe skin and soft tissue infections (SSTIs) are often life-threatening emergencies that require a rapid diagnosis. Gas gangrene is one of the most fulminant types of SSTI and is usually caused by Clostridium perfringens' contamination of an open wound.

Although gas gangrene is usually associated with fecally contaminated wounds, "spontaneous" cases occur and are most commonly caused by Clostridium (C.) septicum. We report a case of spontaneous gas gangrene caused by $C$. septicum that only became manifest while the patient was being monitored in the emergency department. We also review the diagnosis and treatment aspects of this entity.
\end{abstract}

Key words: gas gangrene, Clostridium septicum

\begin{abstract}
RÉSUMÉ
Les infections sévères de la peau et des tissus mous (IPTM) sont souvent des urgences qui mettent la vie en danger et qu'il faut diagnostiquer rapidement. La gangrène gazeuse est l'un des types des plus fulminants d'IPTM et est habituellement causée par la contamination d'une plaie ouverte par Clostridium perfringens.

Même si l'on associe habituellement la gangrène gazeuse à des plaies contaminées par des matières fécales, il se produit des cas "spontanés" qui sont causés le plus souvent par Clostridium (C.) septicum. Nous présentons un cas de gangrène gazeuse spontanée causée par $C$. septicum qui ne s'est manifesté que pendant que l'on surveillait le patient à l'urgence. Nous passons aussi en revue le diagnostic et le traitement de cette affection.
\end{abstract}

\section{Case History}

An 84-year-old diabetic man with a history of penicillin allergy was seen in the emergency department (ED) with a 12hour history of urinary frequency. He denied dysuria, fever or chills, but he had noted pain in his right thigh. His medical history included coronary artery disease and atrial fibrillation. There was a prior history of a gastrointestinal hemor- rhage while on anticoagulation therapy. A colonoscopy at that time had revealed pandiverticulitis; however, the cecum was not visualized.

On initial examination the patient was in no distress and his vital signs were temperature $37.5^{\circ} \mathrm{C}$, pulse 66 beats/ min, respiratory rate 16 breaths /min and blood pressure (BP) $129 / 63 \mathrm{~mm} \mathrm{Hg}$. There was no costovertebral angle or abdominal tenderness. Examination of the testes and prostate

From the *Department of Medicine and Laboratories and the ${ }^{\dagger}$ Department of Emergency Medicine, St. Mary's Hospital, Montréal, Que.

Received: July 3, 2006; revisions received: Oct. 17, 2006; accepted: Oct. 23, 2006

This article has been peer reviewed.

Can J Emerg Med 2007;9(2):133-5 
was unremarkable. The right hip had a normal range of motion with no skin erythema. The urinanalysis showed hematuria but no pyuria. The white blood cell count (WBC) was $19.5 \times 10^{9} / \mathrm{L}$, the hemoglobin was $86 \mathrm{~g} / \mathrm{L}$ and the serum creatinine was $172 \mathrm{mmol} / \mathrm{L}(\mathrm{NR}=44-123)$.

The history of urinary frequency with hematuria and leukocytosis suggested a possible prostatitis and a dose of oral ciprofloxacin $500 \mathrm{mg}$ was given. However, there was some uncertainty surrounding the diagnosis and the complaint of thigh pain was still unexplained, so the patient was kept for overnight observation. Reassessment, performed 2 hours later, indicated an area of erythema over the inner right thigh with some small blister formation. By that time, the patient was in severe pain and a repeat WBC was $25.9 \times 10^{9} / \mathrm{L}$ with an elevated creatine kinase of $700 \mathrm{IU} / \mathrm{L}(\mathrm{NR}=20-180)$. His BP had dropped to $100 / 60 \mathrm{~mm} \mathrm{Hg}$ with a pulse of 110 beats/min. He did not have a fever. His serum lactate was elevated at $12.8 \mathrm{mmol} / \mathrm{L}(\mathrm{N}=0.6-2.4)$.

The diagnosis was changed to necrotizing fasciitis and the patient was started on intravenous (IV) cefazolin, clindamycin and gatifloxacin. A surgical consultation was obtained and the patient was taken to the operating room 8.5 hours after having arrived in the ED. Incisions were made in the thigh and a foul smelling thin exudate was obtained. The underlying muscles were necrotic and a decision was made to perform a disarticulation of the right leg at the hip. Only the anaerobic culture was positive and grew Clostridium (C.) septicum. The initial urine culture grew Acinetobacter baumannii. The patient was given a total of 12 days of combined cefazolin and clindamycin, which was stopped when there was no evidence of residual clostridial infection on clinical and radiologic exam. Almost 3 weeks after undergoing surgery, the patient had a sudden deterioration in his pre-existing cardiac condition and he died. An autopsy was not performed.

\begin{tabular}{l}
$\begin{array}{l}\text { Table 1. Classification of severe skin and soft tissue } \\
\text { infections. }\end{array}$ \\
\hline Non-gas-forming
\end{tabular}

Necrotizing fasciitis type I (group A Streptococcus)

Necrotizing fasciitis type II (synergistic necrotizing cellulitis)

Fournier's gangrene

\section{Discussion}

Life-threatening skin and soft-tissue infections (SSTIs) are infrequent and difficult to diagnose on initial presentation. A useful classification of SSTI uses the presence or absence of gas in the soft tissues (Table 1). Gas can be found either clinically (crepitus) or radiologically, but is usually a later manifestation, often seen when the patient is in shock. Among the gas-forming SSTIs, the pathogens most frequently responsible, either alone or in combination, are Clostridia, other anaerobes and coliforms. Clostridial myonecrosis, or gas gangrene, is the result of infection by exotoxin producing bacteria that invade muscle tissue and result in tissue necrosis and gas production. ${ }^{1}$ Clostridia thrive in an anaerobic environment such as the large intestine. Most cases result from the contamination of an open wound by fecal flora, but infection has been reported postpartum, ${ }^{2}$ after septic abortions or with illicit IV drug use. C. perfringens accounts for $80 \%-95 \%$ of cases that are associated with an open wound.

Spontaneous or nontraumatic gas gangrene is a rare entity and is almost exclusively caused by $C$. septicum, ${ }^{3-9}$ which is aerotolerant and capable of infecting nondevitalized tissue. ${ }^{8}$ The pathogenesis is a hematogenous spread from an intestinal focus, and the portal of entry is believed to be mucosal ulceration or perforation of the gastrointestinal tract. ${ }^{4}$ Bowel pathology, such as carcinoma, diverticulitis, infarction, enterocolitis and volvulus, has been reported. ${ }^{8}$ In one study of patients with $C$. septicum infection, $50 \%$ were found to have a primary malignancy, $75 \%$ of which were colonic; and of those, $40 \%$ were cecal. ${ }^{10}$ Although this patient was not proven to harbour a colonic malignancy, he was anemic with a history of occult lower gastrointestinal bleeding. Previous colonoscopy had been incomplete, with failure to visualize the cecum.

Seeding tends to involve an extremity, but may involve more than one area. ${ }^{11}$ Diabetes or atherosclerotic peripheral vascular disease may result in relative tissue hypoxia sufficient for colonization once seeded. Then a multitude of bacterial toxins overwhelms the host defenses and initiates a cycle of tissue destruction, local ischemia, bacterial proliferation and toxin production. ${ }^{5}$

The incubation period is short, ranging from 6 hours to 3 days with an abrupt onset of illness heralded by rapidly increasing pain. The patient appears toxic with fever and possible delirium. Initial examination of the skin may be relatively unimpressive and the clinician must be vigilant to maintain a high index of suspicion. At onset, the skin may appear edematous and tender, and then blebs or bullae develop containing a thin, dark fluid. The underlying skin

Gas gangrene 
becomes necrotic and changes to a purplish-black colour. Samples of material taken from the infected area will show a paucity of leukocytes and the presence of gram-positive rods on gram stain. C. septicum can be distinguished from $C$. perfringens on gram stain. Both organisms produce toxins that inhibit leukocyte migration and function, and can rapidly cause shock. ${ }^{1}$

Therapy for gas gangrene involves early and aggressive surgical exploration to establish the diagnosis and to remove devitalized tissue, and amputation is often required. Concurrent antibiotic therapy is critical and should be instituted immediately. The recommended regimen includes high dose IV penicillin, 18-24 million units/day in divided doses, and IV clindamycin. ${ }^{12}$ Clindamycin is believed to prevent toxin release and has been shown to be more efficacious than penicillin in an animal model. ${ }^{13}$ Mixed infections are not uncommon so an agent active against gramnegative organisms should also be added until the final bacteriology results are known. The benefit of hyperbaric oxygen therapy in gas gangrene has not been established, but it may play a role as an adjunct to surgical debridement under certain circumstances.

The mortality rate for spontaneous gas gangrene remains high, ranging from $67 \%-100 \%$, and most patients die on the first day of illness. ${ }^{8}$ This patient appeared to have survived his $C$. septicum infection only to die 3 weeks later from unknown causes. The rapid institution of antibiotics and the extensive debridement he underwent were important factors in his short-term survival.

\section{Conclusion}

For successful treatment, it is critical that the emergency physician recognize the disease early in its course. The presence of severe localized pain with or without fever and leukocytosis should raise concern as the characteristic skin changes may not be initially apparent. Current treatment involves high-dose, broad-spectrum antimicrobial therapy combined with timely surgical intervention.

Competing interests: None declared.

\section{References}

1. Stevens DL, Troyer BE, Merrick DT, et al. Lethal effects and cardiovascular effects of purified alpha- and theta-toxins from Clostridium perfringens. J Infect Dis 1988;157:272-9.

2. Dylewski J, Wiesenfeld H, Latour A. Postpartum uterine infection with Clostridium perfringens. Rev Infect Dis 1989;11:470-3.

3. Corey EC. Nontraumatic gas gangrene: case report and review of emergency therapeutics. J Emerg Med 1991;9:431-6.

4. Leung FW, Serota AI, Mulligan ME, et al. Nontraumatic clostridial myonecrosis: an infectious disease emergency. Ann Emerg Med 1981;10:312-4.

5. Kizer KW, Ogle LC. Occult clostridial myonecrosis. Ann Emerg Med 1981;10:307-11.

6. Rich R, Salluzo R. Spontaneous clostridial myonecrosis with abdominal involvement in a non-immunocompromised patient. Ann Emerg Med 1993;22:1477-80.

7. J Delbridge MS, Tarton EP, Kester RC. Spontaneous fulminant gas gangrene. Emerg Med J 2005;22:520-1.

8. Stevens DL, Musher DM, Watson DA, et al. Spontaneous, nontraumatic gangrene due to Clostridium septicum. Rev Infect Dis 1990;12:286-96.

9. Abella BS, Kuchinic P, Hiraoka T, et al. Atraumatic clostridial myonecrosis: case report and literature review. J Emerg Med 2003;24:401-5.

10. Bretzke ML, Bubrick MP, Hitchcock CR. Diffuse spreading Clostridium septicum infection, malignant disease and immune suppression. Surg Gynecol Obstet 1998;166:197-9.

11. Tehrani H, Gillespie PH, Cormack GC. Fatal multifocal metastasis of Clostridium septicum: a case report. Br J Plast Surg 2004;57:673-5.

12. Stevens DL, Maier KA, Mitten JE. Comparison of clindamycin, rifampin, tetracycline, metronidazole, and penicillin for efficacy in prevention of experimental gas gangrene caused by Clostridium perfringens. J Infect Dis 1987;155:220-8.

13. Stevens DL, Maeier KA, Mitten JE. Effect of antibiotics on toxin production and viability of Clostridium perfringens. Antimicrob Agents Chemother 1987;31:213-8.

Correspondence to: Dr. J. Dylewski, Department of Medicine and Laboratories, St. Mary's Hospital, 3830 Lacombe Avenue, Montreal QC H3T 1M5 